\title{
Step-functional Change in Annual Peak Flow Illustrated for the Ishikari River at Hashimoto-chō, Hokkaido
}

\author{
G. H. DURY and Nobuo KoHCHI
}

\begin{abstract}
Analysis designed to test for step functions in time series provides an alternative to cyclic and secular analysis; it also amplifies probability analysis as this is usually practised. For the Ishikari River, step-functional testing identifies blocks of years, with average length 5 years, when annual floods ran generally above, generally below, or generally close to the series mean. Parallel testing for the Wabash River identifies runs of either high or low values, with average length between 4 and 5 years. Separate Gumbel graphs can be drawn for the high-flow and low-flow regimes, and also (if it exists) for the regime close to the mean. While long-term forecasting is not affected by our results, these do suggest great fluctuations in the flood hazard, in the short term.
\end{abstract}

\section{Introduction}

The central purpose of this study is to illustrate the application of a particular method of analyzing time series. The method tests for abrupt changes in magnitude between successive portions of a series. If a test produces positive results, then it identifies a step function in the regime concerned. The method has been successfully applied to climatic and climaterelated series of several kinds-not only those of streamflow, but also those of annual and monthly precipitation, and of tree ring thickness (DURY, 1979, 1980, 1981).

\section{Relationship to Other Methods}

Cyclic analysis of climate on a statistical basis is commonly thought to have begun with the announcement, in 1887, of the well-known Brückner cycle with its period of about 35 years. So many empirical analysts followed in the path of BRÜCKNER, that SHAw (1928) was able to list some 120 periodicities, ranging in length from 1.0 to 260 years. Of these, excluding the 1 -year cycle, some 80 relate to precipitation, and to periods ranging from 1.05 to 171 years.

This early work was handicapped by the limited capacity of the calculators then available. It failed generally to gain acceptance, partly because of the multitude of its claims, partly because many of the periods identified were not simple multiples or fractions of a year, partly because it failed to supply valid predictions, and partly because of the excesses committed by some advocates of a simple sunspot/ climate relationship. Interest in cyclic and related analysis has, with the aid of computers, undergone a revival since World War II. Spectral analysis, for example, has found favour with a number of climatologists. Interest in sunspots and related topics has also revived, partly under the stimulus of our increasing knowledge of the upper atmosphere. A recent illustration is the study of FAIRBRIDGE and Hillaire-MARCEL (1977), which relates the sequence of emerged beaches in Hudson's Bay to a solar magnetic cycle of 45 years in length, i.e., four times the average length of the sunspot cycle.

Cyclic analysis appears not to have attracted investigators of streamflow. To some extent, the same can be said of the search for progressive trends.

In climatology, the attention paid during the early years of this century to the question of progressive trends in precipitation has been largely replaced by attention to trends in temperature.

Meteorologist to some extent, and hydrologists as a group, have paid-and 
continue to pay - a great deal of attention to probability. In meteorology, percentage probability, widely used in hydrology in former times, has been largely superseded in the analysis of streamflow by the calculation of magnitude and frequency, wherein an event of given magnitude is related to a given frequency expressed as a recurrence interval. Although variations and alternatives exist, the commonest method of magnitude-frequency analysis in hydrology is that developed by GUMBEL (1941, 1945, 1958, 1959). Gumbel analysis became standard practice with the Water Resources Division of the United States Geological Survey during the 1950s. It has spread extensively through the world community of hydrologists. Because the method which we shall employ represents a significant elaboration of Gumbel analysis, we shall now outline the method of the latter.

For an annual flood series (i. e., one flood peak per year), the recurrence interval, in years, is calculated for each flood as

$$
T=(n+1) / r
$$

where $T$ is the recurrence interval, $n$ is the number of items in the series, and $r$ is the rank order of a given item. It is a property of the statistical design that the mean annual flood has a recurrence interval of 2.33 years, and the most probable annual flood one of 1.58 years. The calculation involved is extremely simple. Results are plotted on specially designed graph paper, Gumbel paper, as in our Fig. 1, which presents a Gumbel graph for the annual flood series on the Ishikari River, 1951-1979. Flood magnitudes and calculated recurrence intervals are listed in Table 1.

It is usual for the points plotted on a graph to approximate a smooth line, as they do in Fig. 1. In many cases the line is straight, the data then conforming to Gumbel's Type I probability. A concaveup graph indicates Type II probability, a concave-down graph indicates Type III. Especially with Type I probability, it is common for a graph to include one or two very high points at its upper extreme. A recent work of one of the present authors (Консні, 1981) has also shown a similar trend in the case of the Yubari River, Hokkaido, as well as all other major rivers of Japan. The record for the Ishikari River includes the peak discharge of $5730 \mathrm{~m}^{3} \cdot \mathrm{s}^{-1}$ in 1975. Arithmetic calculation assigns this discharge a percentage probability of 3.5 , which is certainly too high. The recurrence interval calculated from the record is 30 years; as the graph clearly shows, this

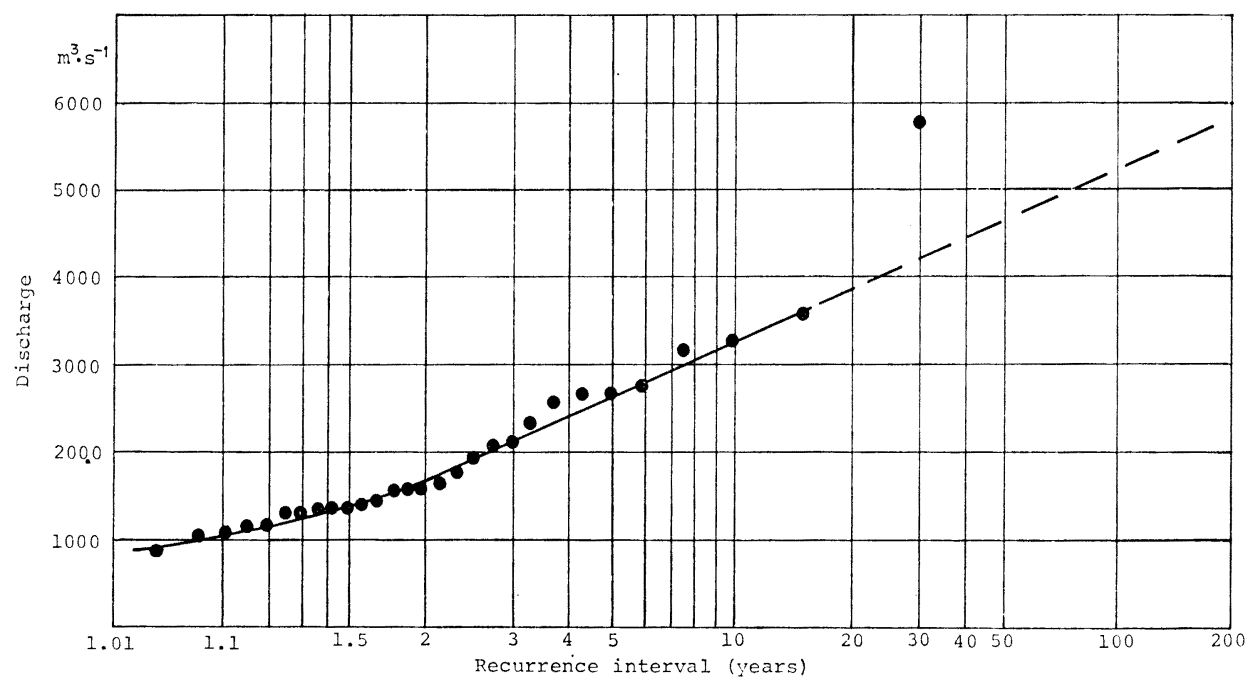

Fig. 1. Gumbel graph for annual floods on the Ishikari River, at Hashimoto-chō, 1951-1979. 
Table 1. Annual floods on the Ishikari River, at Hashimoto-chō, Hokkaido, 1951-1979.

\begin{tabular}{|c|c|c|c|c|c|c|c|}
\hline 1 & 2 & 3 & 4 & 5 & 6 & 7 & 8 \\
\hline \multirow[t]{2}{*}{ Year } & \multirow[t]{2}{*}{$\mathrm{Q}, \mathrm{m}^{3} \cdot \mathrm{s}^{-1}$} & \multirow[t]{2}{*}{$\begin{array}{c}T, \\
\text { years }\end{array}$} & \multirow[t]{2}{*}{$N$} & \multicolumn{2}{|c|}{ Block means } & \multicolumn{2}{|c|}{$\begin{array}{l}r^{2} \text { values for segment } \\
\text { of deviations graph }\end{array}$} \\
\hline & & & & Arithmetic & Transform & Arithmetic & Transform \\
\hline $\begin{array}{l}1951 \\
1952\end{array}$ & $\begin{array}{l}1357 \\
1013\end{array}$ & $\begin{array}{l}1.36 \\
1.07\end{array}$ & 2 & 1185.0 & 10.555 & 1.000 & 1.000 \\
\hline $\begin{array}{l}1953 \\
1954 \\
1955 \\
1956\end{array}$ & $\begin{array}{l}3274 \\
2576 \\
3182 \\
2647\end{array}$ & $\begin{array}{l}10 \\
3.75 \\
7.5 \\
4.29\end{array}$ & 4 & 2919.75 & 14.275 & 0.986 & 0.992 \\
\hline $\begin{array}{l}1957 \\
1958 \\
1959 \\
1960\end{array}$ & $\begin{array}{r}1387 \\
1554 \\
984 \\
1405\end{array}$ & $\begin{array}{l}1.58 \\
1.875 \\
1.03 \\
1.67\end{array}$ & 4 & 1323.5 & 10.970 & 0.985 & 0.969 \\
\hline $\begin{array}{l}1961 \\
1962 \\
1963 \\
1964 \\
1965 \\
1966 \\
1967 \\
1968 \\
1969 \\
1970\end{array}$ & $\begin{array}{l}2089 \\
2674 \\
1061 \\
2308 \\
1539 \\
1728 \\
1305 \\
1363 \\
1574 \\
3572\end{array}$ & $\begin{array}{l}2.73 \\
5 \\
1.11 \\
3.33 \\
1.76 \\
2.31 \\
1.25 \\
1.43 \\
2 \\
15\end{array}$ & 10 & 1921.2 & 12.257 & 0.602 & 0.438 \\
\hline $\begin{array}{l}1971 \\
1972\end{array}$ & $\begin{array}{l}1129 \\
1118\end{array}$ & $\begin{array}{l}1.2 \\
1.15\end{array}$ & 2 & 1223.5 & 10.400 & 1.000 & 1.000 \\
\hline $\begin{array}{l}1973 \\
1974 \\
1975 \\
1976 \\
1977\end{array}$ & $\begin{array}{l}2759 \\
1918 \\
5730 \\
1305 \\
2098\end{array}$ & $\begin{array}{c}{ }^{6} \\
2.5 \\
30 \\
\quad 1.3\end{array}$ & 5 & 2672.0 & 13.538 & 0.757 & 0.839 \\
\hline $\begin{array}{l}1978 \\
1979\end{array}$ & $\begin{array}{l}1364 \\
1616\end{array}$ & $\begin{array}{l}1.5 \\
2.14\end{array}$ & 2 & 1490.0 & 11.410 & 0.979 & 0.895 \\
\hline & & Period & & 1987.14 & 12.275 & & \\
\hline
\end{tabular}

value is far too low. A recurrence interval of about 200 years is far more likely. Needless to say, there is no cause for alarm in the appearance of a 200 -year flood in a record 29 years in length. A similar record for the river Nene in eastern England includes a flood with a recurrence interval of between 500 and 1000 years (Dury, 1973). Gumbel graphs permit events of unusually great magnitude and unusually low frequency to be recognised for what they are.

Probability analysis in general, and Gumbel analysis in particular, has been powerfully promoted, in hydrology, by the need to forecast. This need, in turn, is related to the design of dams, to the planning and regulation of land use on valley floors, and to all aspects of the flood hazard in general.

As we shall now show, however, the results of Gumbel analysis may obscure real variations of regime in the short term. It is these variations that are revealed by step-functional analysis.

\section{Testing for Step Functions}

The first operation is to determine the mean of the time series concerned, thus converting it to stationary form, and to calculate cumulative deviations from that mean. Graphs of cumulative deviations, 
often then called mass curves, were popular among climatologists in the early years of the present century, although not then used as we shall use them here. For instance, KEELE (1917) attempted to apply a mass curve to the investigation of possible periodicity in the flow of the river Nile, his work providing an exception to our statement about the lack of interest in cycles on the part of hydrologists. BARNES (1919) attempted to use mass curves in determining the true long-term means of precipitation series. In the mid-century, KRAUS (1954, $1955 \mathrm{a}, 1955$ b, 1956) constructed a series of graphs for widely distributed stations, reaching conclusions about regional variation of precipitation which deserve additional study; however, his use of cumulative deviations was essentially subjective. Recently, BELL (1980) has drawn attention to the effectiveness of cumulative residuals in the analysis of data on date of wine harvest, vine yield, and wine quality. One of us (DURY, op. cit. $1979,1980,1981$ ) has used them in the analysis of time series of precipitation, grain harvest quality, and tree rings.

When cumulative residuals are graphed, the graph typically appears segmented. A rising limb relates to a run of values that averages above the series mean, a falling limb to a run that averages below that mean.

Experience shows that rising and falling limbs are more common than the horizontal limbs which relate to a run of values close to the series mean. Figure 2 (a) -1 shows an observed series of the annual peak flows on the Ishikari River, and Fig. 2(a)-2 shows a graph of their cumulative residuals.

If analysis is done by computer, then cumulative deviations need not be graphed. It is however a subordinate purpose of the present study to record that step-functional testing can be performed with the aid of a desk calculator. The rising, falling, and horizontal limbs on the graph of cumulative deviations demarcate discrete blocks. Means of successive blocks are tested for significant differences by standard statistical methods. We have used the cutoff of $P=$
0.05 in the $F$ test for difference of variance, and also in the $t$ test for difference of means, except where $N=2$, when we have accepted $\mathrm{P} \leqq 0.10$. Results appear in Table 1 , cols. 4 and 5 . The square wave superimposed on the observed series in Fig. 2 (a) -1 is drawn from the data listed in these two columns.

While it is not essential to fit straight lines to the segments of a deviations graph, satisfactory fitting does help to confirm the identification of the blocks recognized. Steeply rising and steeply falling limbs of the deviations graph usually produce very high correlations between value and serial location (Table 1, col. 7). Low to insignificant correlations occur when values run close to the period mean. For the Ishikari River, 1961-70, the correlation coefficient is significant at the 0.05 level, but the interval is particularly noisy; five years with readings below the series mean are succeeded by a single year (1970) with a very high reading. Here is a source of difficulty: the difference-of-means test cannot handle blocks of only one bit length.

\section{Transformation for Normalization}

For series where values below zero are impossible, as with precipitation and streamflow, difficulties can arise when the series mean is low, but when the actual record includes some very high values. The highest value in the series here used for the Ishikari River is $3743 \mathrm{~m}^{3} \cdot \mathrm{s}^{-1}$ above the series mean, whereas the lowest value is only $1003 \mathrm{~m}^{3} \cdot \mathrm{s}^{-1}$ below. Since the series mean is $1987 \mathrm{~m}^{3} \cdot \mathrm{s}^{-1}$, it is impossible for the departures of high extremes to match those of low extremes, while for blocks with low block means, it is possible for observed values to be other than normally distributed about their collective means. For this reason, a great deal of climatological analysis replaces observed values by transformed values, the cube-root transformation being widely used. In this particular case, the employment of cube-root transformation makes no difference to the eventual outcome Table 1, cols. 6 and 8 , 
(a) -1
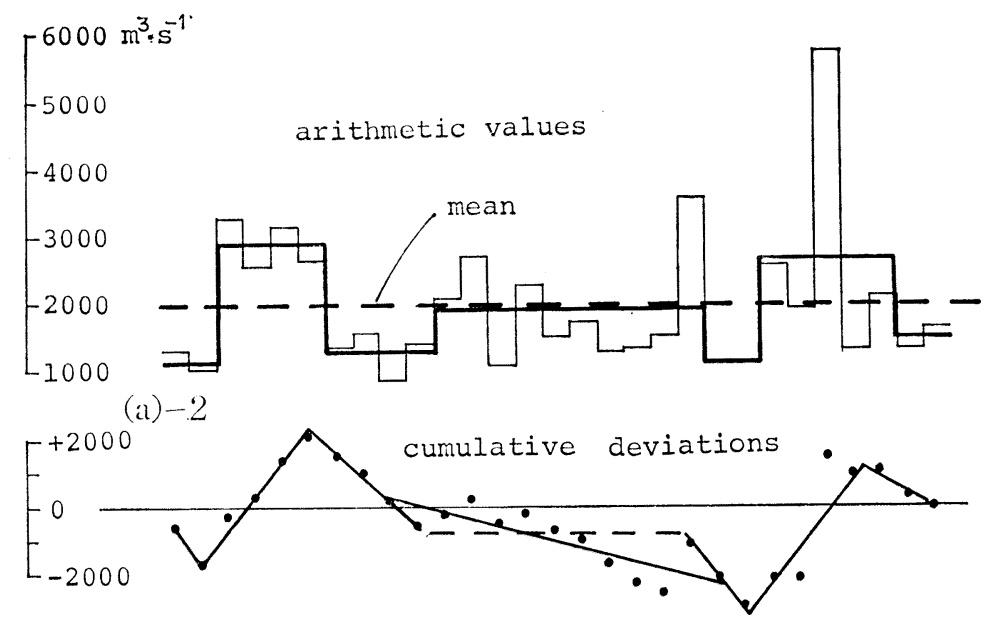

(b) -1

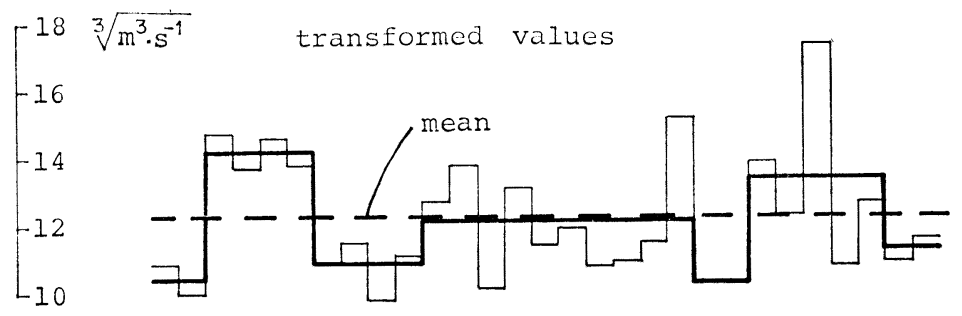

(b) -2 cumulative deviations
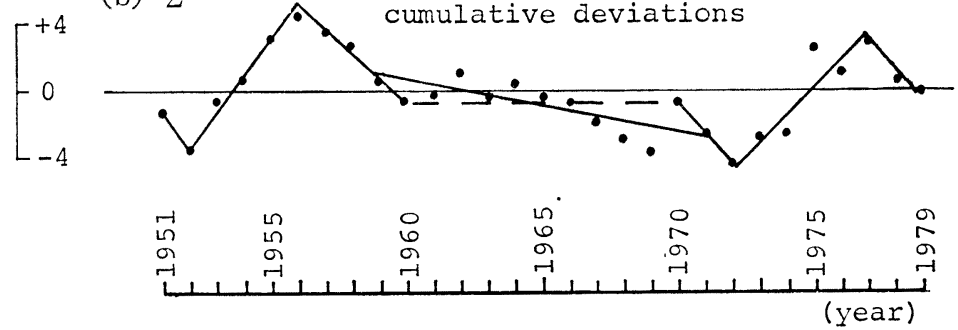

Fig. 2. Observed series, step functions, and cumulative deviations for annual floods on the Ishikari River: arithmetic values in (a) $-1,2$, cube-root transformed values in (b) $-1,2$.

and Fig. 2, lower part). For the Ishikari, the arithmetic residuals from the block means approximate closely a Poisson distribution, while the transformed residuals resemble a normal distribution (Fig. 3). The sample here is too small to reveal at all clearly the typical skew of a distribution of arithmetic residuals, such as comes out well in the analysis of larger samples (DURY, op. cit. 1980); but even here, regression of the transformed values on their block means can be shown to produce correlation coefficient, $\mathrm{r}=+0.692$, and coefficient of determination, $r^{2}=0.478$, the latter value being insignificantly different from the 0.500 that would indicate a perfect normal distribution.

\section{A Comparison: the Wabash River}

The five completed blocks in the Ishikari 

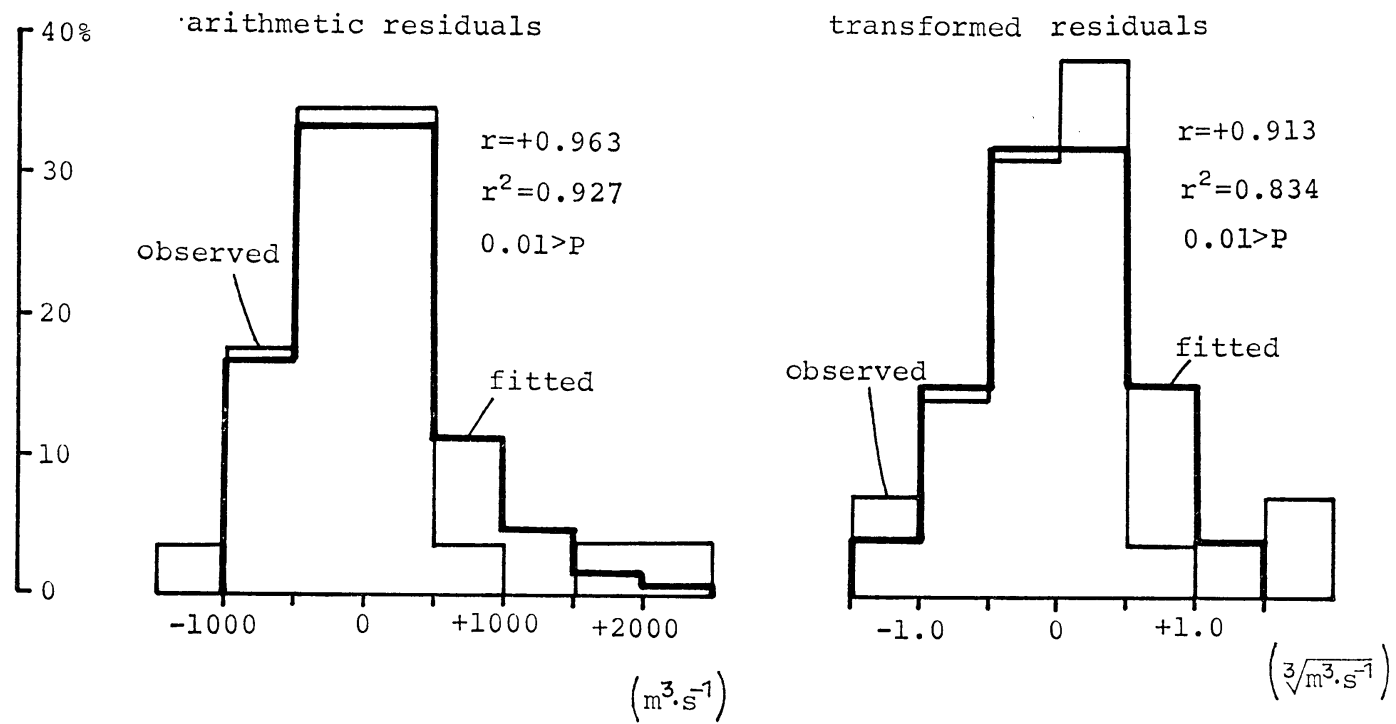

Fig. 3. Residuals from the step-functioning block means, Ishikari River: arithmetic residuals fitted to a Poisson curve, transformed residuals to a normal curve. $r$ indicates the correlation coefficient between observed values and fitted values. $r^{2}$ indicates the coefficient of determination between them.

River series average 5 years in length. This could be a minimum value, since there is no way of determining, from the record used, the length of the blocks to which 1951-52 and 1978-79 belong. We therefore introduce, for purposes of comparison, the annual flood series for the Wabash River at Lafayette, Indiana, 19241957. This series is selected as being comparable in length to that used for the Ishikari River (34 against 29 years), as relating to an arithmetic mean peak not grossly different from that of the Ishikari (some $1470 \mathrm{~m}^{3} \cdot \mathrm{s}^{-1}$, against some $1987 \mathrm{~m}^{3}$. $\mathrm{s}^{-1}$ ), as mainly not overlapping in time, and, above all, as having been used by one of us (DURY, 1969) in illustrating the construction of Gumbel graphs and in demonstrating Gumbel analysis. As the cited report shows, all but the highest of the points on the Gumbel graph for the Wabash plot close to a straight line, indicating Type I probability. When, however, the data for the Wabash are tested for step functions, the results are those shown in Fig. 4; the 34-year series breaks down into eight blocks, of average length
4.25 years. This again is a minimum value, since the first and last blocks are potentially incomplete.

Analysis of many additional series is of course required: one of us (DURY) is in fact working on a selection of unusually long records. Meanwhile, for the rivers discussed here, it is possible to distinguish among regimes. For the Wabash we may recognise an alternation between high and low regimes of annual floods, and construct separate Gumbel graphs for the two (Fig. $5)$. The means of the two regimes differ significantly from one another, and also from the mean for the whole series (Table 2). Three separate Gumbcl graphs can be drawn for the Ishikari, for high, medium, and low regimes (Fig. 6), although only when the isolated peak discharge of 1970 is regarded as anomalous; or alternatively, if differences of means are accepted where $0.01>\mathrm{P}>0.05$. As Table 3 shows, the means for the high and low regimes differ significantly from one another and from the series mean, when the cutoff of $\mathrm{P} \leqq 0.05$ is applied, while the mean for the medium regime is expectably very close to the 


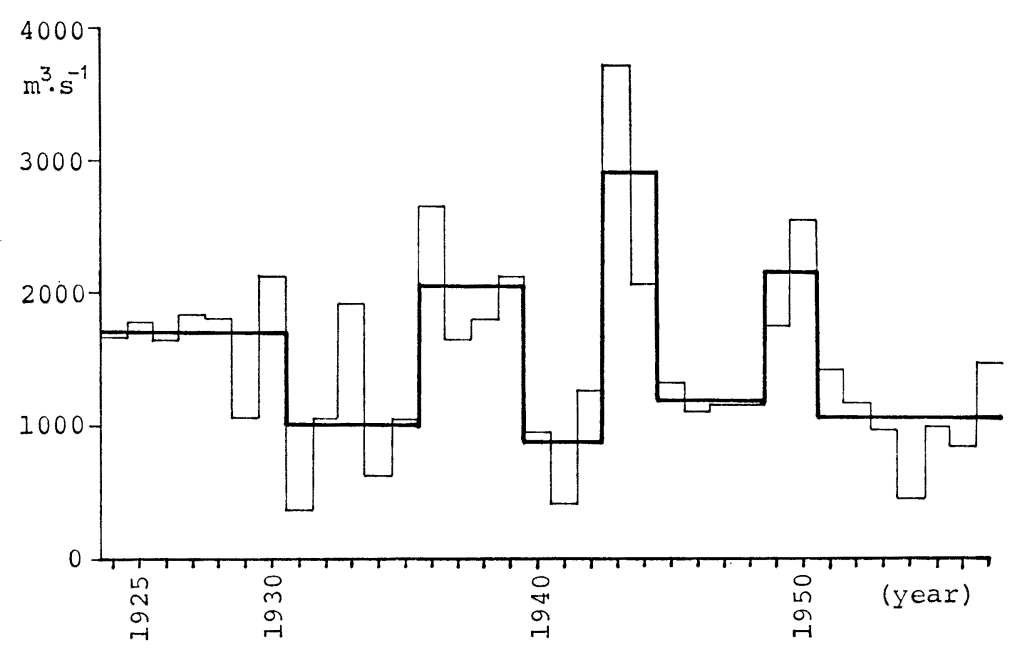

Fig. 4. Step-functional variation of the annual flood regime on the Wabash River at Lafayette, 1924-1957 (cf. Fig. 2)

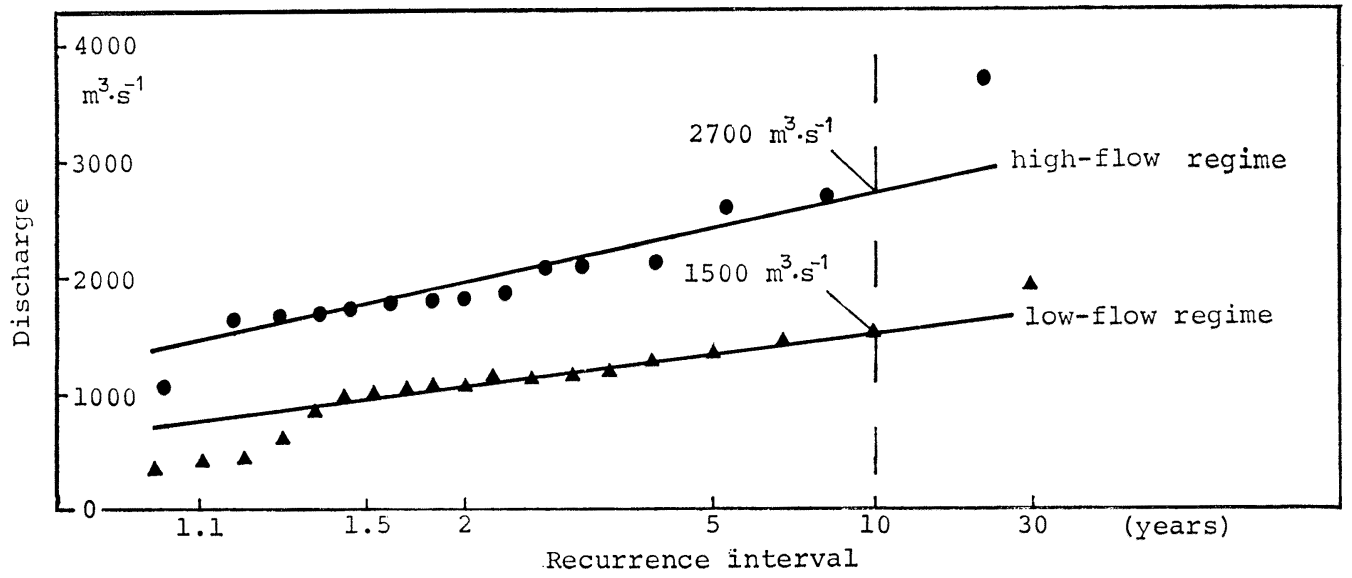

Fig. 5. Gumbel graphs for high-flow and low-flow regimes on the Wabash River.

series mean. The means for the high and low regimes do not however differ significantly from the mean for the medium regime at the indicated level of probability. Calculations with cube-root transformation can be shown to indicate a significant difference between the low and the medium regimes, and a marginally insignificant difference $(N=19, t=2.081)$ between the medium and the high regimes. The arithmetic calculations in particular are affected, as to their outcome, by the isolated high peak flow of 1970 , and to a lesser extent by the high variance of the high regime.
We think it likely that a longer record would serve to damp out some of the effect of the 1970 event, and are accordingly prepared, at least provisionally, to identify three contrasted regimes.

Predictions based on the various magnitude-frequency graphs differ widely, even in respect of the 10-year flood: values for this flood are entered on the diagrams.

\section{Implications}

The abrupt alternation of regime indicates that, with the onset of high flow, the flood hazard is suddenly increased. While 


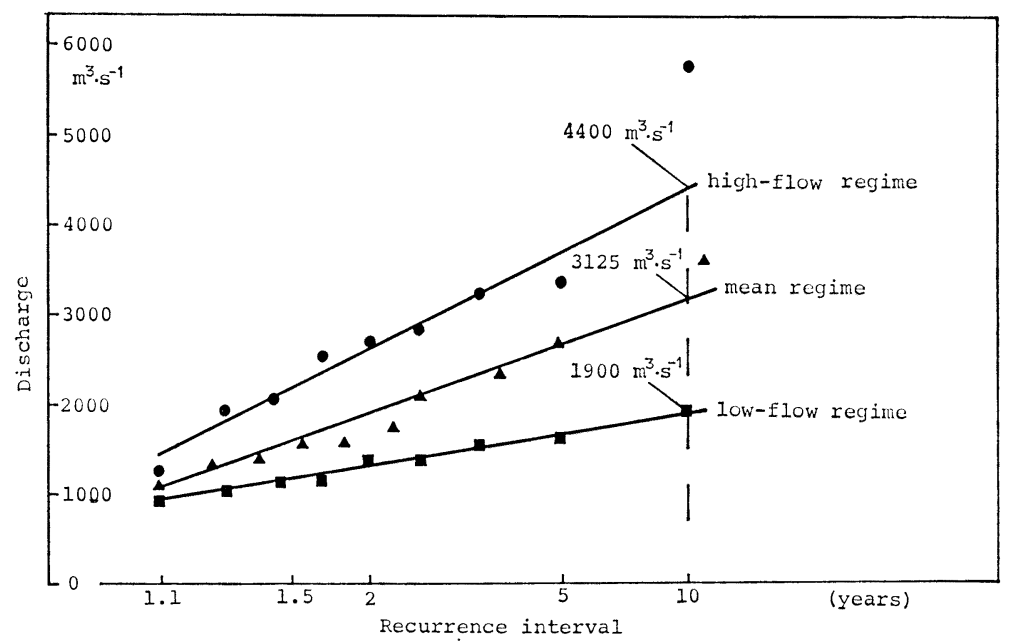

Fig. 6. Gumbel graphs for high-flow, mean, and low-flow regimes on the Ishikari River (cf. Fig. 5). The 10-year floods for the high-flow and low-flow regimes in the two cases differ by an approximate factor of two.

Table 2. Regimes on the Wabash River $\left(\mathrm{m}^{3} \cdot \mathrm{s}^{-1}\right)$

\begin{tabular}{l|c|c|c|c|c|c|c|c}
\hline Regime & $N$ & $\bar{x}$ & $\sigma$ & $F$ & & $\sigma \bar{x}_{1}-\bar{x}_{2}$ & $t$ & $0.05 \geqq \mathrm{P} ?$ \\
\hline High & 15 & 2014.13 & 581.655 & 1.362 & $\sigma_{1}=\sigma_{2}$ & 205.921 & 2.635 & Yes \\
Series & 34 & 1471.53 & 678.847 & 3.254 & $\sigma_{1} \neq \sigma_{2}$ & 147.757 & 2.899 & Yes \\
Low & 19 & 1043.16 & 376.316 & 2.389 & $\sigma_{1} \neq \sigma_{2}$ & 178.979 & 5.425 & Yes \\
High & 15 & 2014.13 & 581.655 & & & & & \\
\hline
\end{tabular}

Table 3. Regimes on the Ishikari River $\left(\mathrm{m}^{3} \cdot \mathrm{s}^{-1}\right)$

\begin{tabular}{|c|c|c|c|c|c|c|c|c|}
\hline Regime & $N$ & $\bar{x}$ & $\sigma$ & $F$ & & $\sigma \bar{x}_{1}-\bar{x}_{2}$ & $t$ & $0.05 \geqq \mathrm{P} ?$ \\
\hline High & 9 & 2832.11 & 1179. 795 & 1.370 & $\sigma_{1}=\sigma_{2}$ & 412.064 & 2.050 & Yes \\
\hline Series & 29 & 1987.21 & 1007.853 & 23. 385 & $\sigma_{1} \neq=\sigma_{2}$ & 202.471 & 3.426 & Yes \\
\hline Low & 10 & 1292.70 & 208.415 & 32.045 & $\sigma_{1} \neq \sigma_{2}$ & 401.199 & 3.837 & Yes \\
\hline High & 9 & 2832.11 & 1179.795 & 2.624 & $\sigma_{1}=\sigma_{2}$ & 469.257 & 1.941 & No \\
\hline Medium & 10 & 1921.30 & 721.443 & 11.982 & $\sigma_{1} \neq \sigma_{2}$ & 250.315 & 2.050 & No \\
\hline Low & 10 & 1292.70 & 208.415 & & & & & \\
\hline Medium & 10 & 1921.30 & 721.443 & 1.951 & $\sigma_{1}=\sigma_{2}$ & 354.944 & 0.186 & No \\
\hline Series & 29 & 1987. 21 & 1007.853 & & & & & \\
\hline
\end{tabular}

The calculations for these Tables were carried out to more decimal places than are shown.

$N$ : number of observations

$\bar{x}$ : mean for the regime

$\sigma:$ standard deviation for the regime

$F:\left(\sigma^{\prime} / \sigma^{\prime \prime}\right)^{2}$, where $\sigma^{\prime}$ is the greater value. Results of the $F$ test are indicated as presence/ absence of a significant difference between the variances

$\sigma \bar{x}_{1}-\bar{x}_{2}:$ standard deviation of differences between the means

$t$ : calculated in the usual way as $\left(\bar{x}^{\prime}-\bar{x}^{\prime \prime}\right) / \sigma_{x_{1}}-x_{2}$ 
the predictive value of step-functional analysis is not superior to that of Gumbel analysis in the long term, the latter seems to be potentially misleading in the shortterm context. We seem to be dealing in this context with the attribute of persistence. For the time being, however, either a persistence factor, or a probability function attached to it, is not identifiable.

A probability function could well apply to the length of block. Analysis in progress by one of the authors (DURY) suggests that, for many rivers with long records, the average length is about 12 years, although much remains to be done in the investigation of the effects of drainage area and of lakes within a system. In some long series, individual blocks range in length up to some 40 years. Unless some probability function can be attached not only to block length but also to the incidence of switching from one type of regime to another, the prospects of forecasting on a step-functional basis seem to be remote in the extreme. Meanwhile, our findings suggest that probability forecasting by the Gumbel technique should be based on a minimum of 50 years of record, in order to use data from four blocks of average length. Step-functional variation of regime appears to increase the uncertainty which is known in any case to apply to magnitudefrequency analysis, and to become greater in relation to the higher range of recurrence interval.

\section{Acknowledgement}

We would like to acknowledge helpful discussions with Professors W. A. R. Brinkmann and G. WaнвA (University of Wisconsin-Madison), and Barbara Bell (Harvard Solar Observatory). Thanks are due to the officers of the Ishikari River Authority, Hokkaido Development Bureau, for the data of discharge of the Ishikari River at Hashimoto-chō.

\section{摘要}

時系列解洒の手法のうち, 周期解析や長期変動解析 にかわるものとして, step function にもとづく解析 手法を, 年間最大淇水流量の系列に適用し, 洪水伦険 度の確率評価問題について考察した。

石狩川の橋本町地点における 29 年間のデータにつ
いて, step-functional な仮説検定をした結果, 2 〜 10年 (平均 5 年) の長さで, 系列の平均值より, 一般 に大きかったり，一般に小さかったり，あるいは平均 值に近かったりする年の連なりが認められた。 また， 同様な検定を Wabash 川（合衆国，インディアナ州） の Lafayette 地点における34年間のデータについて 行なうと，2〜 7 年 (平均 4.25 年) の長さで, 系列の 平均より, 一般に大きい年 (高水レジーム) と小さい 年 (低水レジーム) の連なりが浔められた。 これらの レジームについて, 別々の Gumbel グラフが描け, 同じ流量に対する確率年の評洒值は, 各レジームでか なり異なり，短期的にみた洪水の危険度には大きな変 動があると解播した。

\section{References}

Barnes, A. A. (1919) : Rainfall in England: the true long-average as deduced from symmetry. Quaterly Journal, Royal Meteorological Society, 45: 209-227.

Bell, B. (1980) : Analysis of viticultural data by cumulative deviations. Journal of Interdisciplinary History, 10: 851-858.

Dury, G. H. (1969) : Hydraulic geometry. p. 319329. In: R. J. Chorley (ed.), Water, Earth, and Man, Methuen \& Co.

Dury, G.H. (1973) : Magnitude-frequency analysis and channel morphometry. p. 91-121. In: M. Morisawa (ed.), Fluvial Geomorphology, State University of New York at Binghamton.

Dury, G. H. (1979) : A century of rainfall records re-analyzed. Transactions, Société Guernèsiase, 20: 490-493.

Dury, G.H. (1980) : Step-functional changes in precipitation at Sydney, N.S. W. Australian Geographical Studies, 18: 62-78.

Dury, G.H. (1981) : Climate and settlement in late-medieval central England. p. 40-53. In: C. Delano Smith and M. Parry (eds.), Consequences of Climatic Change, Department of Geography, Universityof Nottingham.

Fairbridge, R. W. and C. Hillaire-Marcel (1977) : An 8,000-yr palaeoclimatic record of the 'Double-Hale' 45-yr solar cycle. Nature, 268: 413-416.

Gumbel, E. J. (1941) : The return period of flood flows. Annals of Mathematical Statistics, 12: $163-190$.

Gumbel, E. J. (1945) : Floods estimated by probability method. Engineering News-Record, 134: 833-837.

Gumbel, E. J. (1958) : Statistical theory of floods and droughts. Journal of the Institution of Water Engineers, 12: 157-184.

Gumbel, E.J. (1959): Communications on the statistical theory of floods and droughts. Journal of the Institution of Water Engineers, 
13: 71-102 (discussions of the 1958 paper, with author's response).

KeEle, T. W. (1917) : Investigation of the Nile River flood-record for traces of periodicity. Minutes of Proceedings, Institution of Civil Engineers, 202: 389-394.

Конснг, N. (1981) : Wavelength of free meanders in Japan: A multiple regression analysis. Geographical Sciences, no. 36: 16-22. (in Japanese).

Kraus, E. B. (1954) : Secular changes in the rainfall of SE Australia. Quarerly Journal, Royal Meteorological Society, 80: 590-601.

KRAUS, F. B. (1955a) : Secular changes of tropical rainfall regimes. Quaterly Journal, Royal Meteorological Society, 81: 198-210.

KRAUS, E. B. (1955b) : Secular changes of east- coast rainfall regimes. Quaterly Journal, Royal Meteorological Society, 81: 430-439.

Kraus, E. B. (1956) : Graphs of cumulative residuals. Quaterly Journal, Royal Meteorological Society, 82: 96-98.

Shaw, Sir Napier (1928) : Manual of Meteoro$\log y$, II, 320-324.

(著者: G.H. デューリー，ウイスコンシンーマジソ ン大学名誉教授，イギリス；河内伸夫，鈴峯女子短期 大学, 広島市西区井口; G. H. Dury, Risby, Bury St. Edmunds, Suffolk IP28 6QN, England; Nobuo Конснг, Suzugamine Women's College, Inokuchi, Nishi-ku, Hiroshima 733)

Accepted: 31 March 1982 